\title{
A VIDA DE ALUNOS PESCADORES DA COMUNIDADE DE BAIACU (BAHIA) E SUA RELAÇÃO COM A ESCOLA: DOIS MUNDOS DISTINTOS?
}

\section{The fisherman-student lifestyle at Baiacu community (Bahia, Brazil) and their relationship with school: two different worlds?}

Nelson Rui Ribas Bejarano ${ }^{1}$ • Joana Maria Soler Brunet ${ }^{2}$ • Fábio Pedro Souza de Ferreira Bandeira ${ }^{3}$. Simone Terezinha Bortoliero ${ }^{4}$

Resumo: A pesquisa analisa o conhecimento da biologia de crustáceos de jovens de uma comunidade pesqueira de Baiacu, Bahia, construído através de seu cotidiano na lida com a pesca. Esses jovens também são alunos de uma escola pública. As atividades pesqueiras em Baiacu envolvem a captura de crustáceos de várias espécies. Já na escola, além da dificuldade de acesso, o ensino é desinteressante para aqueles que vivem da pesca. Os dados foram obtidos através de observação direta e atividades na própria escola, conversas informais e visitas à comunidade. Verificou-se que não há formas estáveis de diálogos entre os saberes tradicionais e escolares. De maneira que os saberes tradicionais, apesar de culturalmente relevantes, não são levados em conta quando se desenvolve o ensino na escola. Os prejuízos são evidentes para os dois mundos. Ao final, indicamos alguns caminhos que possam levar ao início de trocas entre esses dois campos de conhecimento.

Palavras-chave: Ensino de ciências. Etnobiologia. Conhecimento tradicional. Conhecimento escolar. Pescadores artesanais.

Abstract: This research analyzes the ethnobiological knowledge about crustaceans of young people in a fishing community in Baiacu, Bahia, constructed through their daily lives in fishing. The young people are all students at a public school. Fishing activities in Baiacu involve the capture of several crustacean species. The school is hard to access and its teaching is not attractive to those who make their living from fishing. Data was collected through direct observation and activities conducted at the school, as well as informal conversations and visits to the community. We found that no stable forms of dialogue exist between the school and traditional knowledge. This means that, although traditional knowledge is culturally relevant, it is not taken into account in the school's teaching. Losses are evident for both of these worlds. Finally, we indicate certain pathways which may lead to an initial exchange between these two fields of knowledge.

Keywords: Science teaching. Ethnobiology. Traditional knowledge. School knowledge. Artisanal fisherman.

\footnotetext{
${ }^{1}$ Universidade Federal da Bahia (UFBA), Instituto de Química, Departamento de Química Geral e Inorgânica, Rua Barão de Geremoabo, s/n, sala 224, Ondina, CEP 40170-290, Salvador, BA, Brasil. E-mail: bejarano@ufba.br

${ }^{2}$ Ensino secundário da Comunidad Autónoma de las Illes Balears, Espanha.

${ }^{3}$ Universidade Estadual de Feira de Santana, Núcleo de Pesquisa Ambiente, Sociedade e Sustentabilidade, Feira de Santana, BA, Brasil.

${ }^{4}$ Universidade Federal da Bahia (UFBA), Faculdade de Comunicação, Salvador, BA, Brasil.
} 
Bejarano, N. R. R. et al.

\section{Introdução}

Esse texto é parte de uma dissertação de mestrado cujo trabalho de campo foi realizado na Ilha de Itaparica, Bahia, Brasil, dividindo-se entre o dia a dia da Escola Carneiro Ribeiro e a comunidade pesqueira da localidade conhecida como Baiacu. O objetivo inicial da pesquisa foi verificar e analisar o processo do ensino de ciências nessa escola, como parte das exigências acadêmicas para a obtenção da certificação para o mestrado do Programa de Pósgraduação em Ensino, Filosofia e História das Ciências da Universidade Federal da Bahia (UFBA) e da Universidade Estadual de Feira de Santana (UEFS). Ocorreu que, ao chegarmos à escola e iniciarmos os contatos visando o desenvolvimento da pesquisa proposta, tomamos conhecimento de que, em uma das turmas que seriam observadas na pesquisa, formada por participantes do projeto de educação de Jovens e Adultos que se desenvolvia nessa escola, havia uma grande quantidade de alunos trabalhadores.

A pesquisa toma novo rumo ao se constatar que o trabalho desses alunos estava ligado à pesca tradicional em região de manguezal, que são ecossistemas que se caracterizam pela alta produtividade biológica e que prestam um conjunto de bens e serviços ecológicos como: depuração e reciclagem de dejetos, estabilização da linha da costa contra a invasão do mar, proteção contra a erosão das margens dos rios, regulação de ciclos biogeoquímicos, berçário de muitas espécies e que contribuem para a cadeia alimentar das águas costeiras (SCHAEFFER-NOVELLI, 1995). Os problemas que cercam os manguezais são também amplamente conhecidos: pesca predatória, aterro, desmatamento, poluição química e por dejetos domésticos, impactos da maricultura etc.

Um novo desenho de pesquisa foi estabelecido a partir dessas reflexões, já que era possível articular o cotidiano dos jovens pescadores com o ensino de ciências praticado na escola. Desse modo, o projeto buscou conhecer e analisar as concepções ou ideias que esses pescadores tinham sobre algum aspecto da biologia, ecologia ou história natural de espécies selecionadas, relacionadas ao contexto da pesca. Além disso, se buscou verificar, também, se os estudantes traziam para a sala de aula esses conhecimentos, bem como estes são tratados pela escola. Do conjunto de atividades desenvolvidas para a pesquisa de mestrado de Brunet (2006), destacaremos, para este artigo, apenas aquela que envolveu o trabalho com cartões com desenhos de braquiúros e identificação, pelos alunos, das espécies contidas nesses cartões.

\section{O construtivismo}

No auge do movimento conhecido como construtivismo - anos 80 s e 90 s do século $\mathrm{XX}$-, seria considerado como grave erro os professores não se interessarem pelo conhecimento que os alunos possuíam antes do contato formal com os conteúdos escolares (DRIVER et al., 1989). A quantidade de pesquisas feitas sobre o que se convencionou chamar de concepções espontâneas fazia parte de um 'pacote pedagógico' que incluía, então, essas ideias prévias, o respeito do professor por essas ideias, mais do que isso, a inclusão, nos processos de ensino, de atividades de levantamento dessas ideias pré-escolares. Por algum momento, chegou-se a pensar que o problema da aprendizagem de conceitos científicos teria chegado a uma solução. Tendo o professor um papel mais recuado em relação ao ensino tradicional, já que a 
ele caberia orientar o aluno nesse processo de construção, que se iniciaria com a posse das ideias prévias, respeitando-as primeiramente, organizando um ensino em que o aluno pudesse interagir com os objetos do conhecimento e, sobretudo, ajudando os alunos a "construir" seu próprio conhecimento. Não é objetivo deste trabalho se debruçar sobre questões ligadas à história do movimento construtivista, suas características e, sobretudo, a variedade de diferentes enfoques que acabou por assumir. O número especial da revista Science \& Education (1997) trata dessas questões sobre o construtivismo. Uma visão crítica sobre essa escola de pensamento encontra-se em Duarte (2005); indicamos essas referências bibliográficas para quem quiser se aprofundar sobre o assunto.

O principal legado, portanto, do construtivismo é o de que o educador não deve minimizar ou se omitir em relação aos conhecimentos que seus alunos já possuem previamente. Além disso, alguns estudos de caso realizados em áreas rurais do Brasil (BAPTISTA; ELHANI, 2006; PERRELLI, 2008), bem como trabalhos teóricos discutindo a questão da relação entre conhecimento indígena/tradicional e ciência formal no contexto da educação científica (EL- HANI; BANDEIRA, 2008), a partir das ideias do multiculturalismo, têm contribuído para o aprofundamento desse campo do ensino de ciências e sua relação com a etnobiologia na última década (BAPTISTA, 2010; TRÉZ, 2011).

A despeito dessas visões educacionais que apontam para o apoio às ideias trazidas pelos estudantes para a sala de aula, e poderíamos acrescentar, grosso modo, a produção de um ensino contextualizado que envolveria a perspectiva Ciência, Tecnologia e Sociedade CTS, por exemplo, ou, mais recentemente, CTSA - Ciência, Tecnologia, Sociedade e Ambiente, a escola tem se mantido impermeável aos contextos de vida dos alunos. De maneira que, claramente, podemos verificar uma clivagem entre a vida escolar, apoiada nos conteúdos escolares somente, e a vida cotidiana dos alunos, nesse caso, apoiada por conhecimentos tradicionais que não são chamados a dialogar com os conteúdos escolares.

A partir do exposto, a pesquisa realizada tem como hipótese central: os conhecimentos tradicionais dos alunos pescadores de Baiacu são detalhados e sofisticados, envolvendo, também, uma visão de preservação do ambiente em que moram. Por outro lado, a escola, ao permanecer refém dos conteúdos chancelados pelos programas e, especialmente, pelos livros didáticos, não tem sido capaz de incorporar os conhecimentos tradicionais de seus alunos na organização de seu ensino. O prejuízo, se é que podemos chamar assim, é que ir para a escola, para os alunos trabalhadores, passa a ser uma tarefa enfadonha que apenas se justifica pela busca da certificação oferecida pelo sistema escolar. Há uma descontinuidade nas suas vidas: o conhecimento que dominam e que sustenta seus modos de vida é válido apenas em suas vidas extraescola. Por outro lado, o conhecimento escolar é visto como importante apenas dentro dos muros da instituição de ensino.

\section{Metodologia}

A fase de campo da pesquisa foi realizada entre os meses de março e junho de 2006. Envolveu várias ações no âmbito da escola e, também, na comunidade onde moravam os alunos escolhidos como sujeitos. De todo modo, vamos nos reportar apenas a uma das atividades desenvolvidas na escola. 
Bejarano, N. R. R. et al.

Dentre as várias turmas da escola, optamos para a escolha dos sujeitos da pesquisa pelos estudantes do Segmento A do Programa de Regularização do Fluxo Escolar (PRFE); esses alunos estão, no geral, na faixa etária entre 13 e 19 anos e matriculados na $5^{\text {a }}$ série regular, podendo ser provenientes da $4^{a}$ série, do PRF de $1^{a}$ a $4^{a}$ série ou repetentes da $5^{a}$ série. Os professores da escola nos informaram que essa turma era formada "por $90 \%$ de moradores da comunidade de Baiacu" (professora Creuza, de Português). Como já dissemos, essa característica desses sujeitos acabou por ser determinante para os rumos da pesquisa.

Apresentaremos, a seguir, nossos alunos, com os devidos pseudônimos e idades, na época da pesquisa. Utilizamos pseudônimos para proteger as identidades desses alunos bem como de todas as outras pessoas citadas nesse trabalho: João (17 anos), Bruno (18 anos), Antônio (15 anos), Gilmar (16 anos), Camilo (18 anos), Juliano (16 anos), Rafael (16 anos), Simone (34 anos), Eraldo (14 anos), Roberto (15 anos), Pedro (13 anos). Olival, Orlando e Sebastião pertenciam a outras classes, e suas idades não foram reveladas. Por fim, havia, ainda, Carlos, que pertencia ao próprio segmento A do PRF, também de idade não revelada.

\section{A pesquisa no âmbito da escola}

A turma escolhida tinha péssima avaliação tanto por parte dos professores como também da direção da escola. O próprio PRFE tentava contornar a situação de multir-repetências e de desmotivação acadêmica. Enfim, esses alunos, com esse perfil escolar, passaram a colaborar com nossa pesquisa. O desenvolvimento da pesquisa com esses sujeitos também representava uma perspectiva de melhora no rendimento escolar, pelo menos no que tange a avaliação do staff escolar.

O Projeto de Regularização do Fluxo Escolar (PRFE), integrante do Programa Educar para Vencer (PEV), trabalha com classes de $5^{a}$ a $8^{a}$ série e tem como seu objetivo geral a prevenção ou correção do fluxo escolar. Esses projetos/programas derivam de avaliações que incentivavam políticas públicas, inicialmente, propugnadas pela ONU e Banco Mundial na década de 90 do século XX, principalmente, e, em seguida, adotadas pelos países signatários (CRUZ; BARROS, 2008).

Várias atividades foram desenvolvidas com os alunos pescadores de Baiacu. Pelas limitações impostas pelo espaço desse texto, vamos indicar apenas uma das atividades: a atividade com o uso de cartões. Esses cartões (Figuras 1 e 2) foram utilizados em entrevistas semiabertas. Os cartões contêm cinco espécies de crustáceos Decapoda: Brachyura, doravante referidos, simplesmente, como braquiúros. O protocolo de entrevista completo constou das seguintes perguntas: Reconhece o animal desse desenho? Como reconheceu que se trata de um ......?; o que é que lhe ajudou a identificar o desenho? Onde ele mora? Como é a toca dele? O que é que ele come? Como sabe isso? Como percebem tão rápido a gente? Respira? Distingue o macho e a fêmea? Onde desova a fêmea? Sabe se ele muda? Ouviu falar de caranguejode-leite? Ouviu falar que o caranguejo está mole? Capturam qualquer um? 
Figura 1. A. Goniopsis cruentata; B. Ucides cordatus; e C. Callinectes sp.

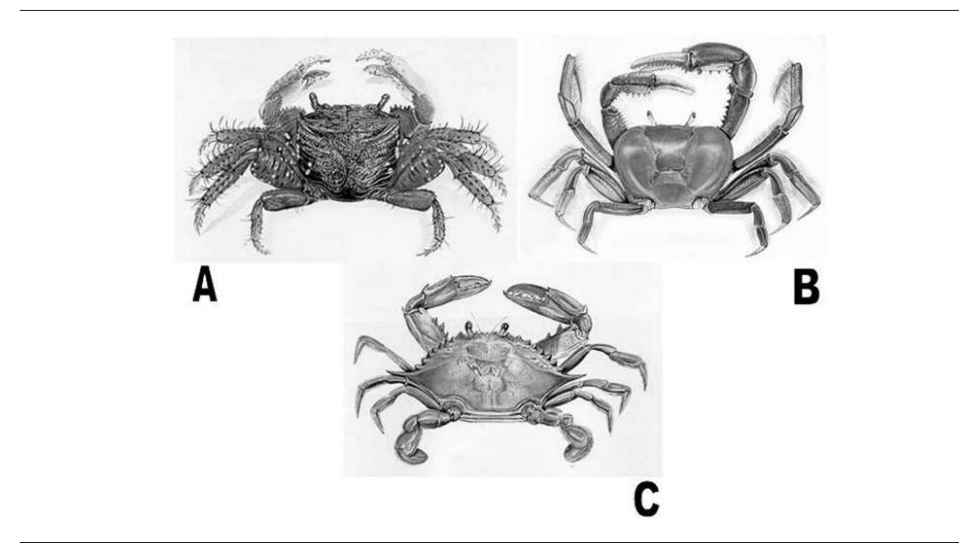

Fonte: Rodrigues (1995).

Figura 2. A. Cardisoma guanhumie B. Uca rapax.

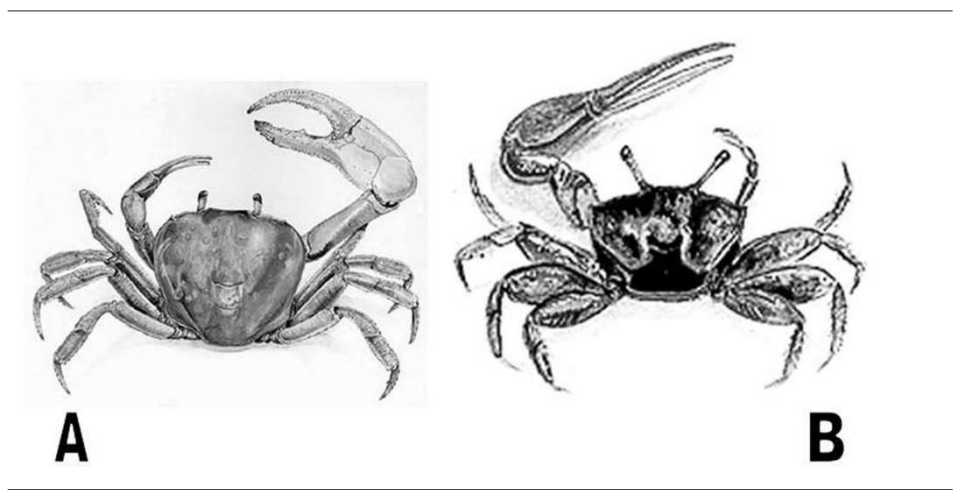

Fonte: Rodrigues (1995).

\section{A atividade com os cartões: identificação de espécies de braquiúros}

As referidas entrevistas foram conduzidas a partir da observação dos desenhos de 5 espécies de braquiúros que Rodrigues (1995) destaca no conjunto da fauna do manguezal (figuras 1 e 2): "aratu" (Goniopsis cruentata), o "caranguejo-uçá" (Ucides cordatus), o "siri" (Callinectes sp.), o "guaiamum" (Cardisoma guanbumi) e uma espécie de "chama-maré" (Uca sp.) Os desenhos, apresentados em branco e preto um após o outro e seguindo a ordem indicada, eram observados pelos estudantes, aos quais se solicitava identificar a espécie que o desenho representava e explicar quais os critérios que utilizavam para identificá-la.

Tomando em consideração as reflexões metodológicas de Campos (2002), tentou-se transformar as entrevistas em "interlocuções entre especialistas" com os objetivos de: 1) na medida do possível, evitar que a ferramenta recortasse os saberes dos estudantes nos padrões 
Bejarano, N. R. R. et al.

acadêmicos e, portanto, perdendo informação da "realidade dos estudantes", uma vez que "não existe uma correspondência unívoca entre nossas áreas ou especialidades e aquelas próprias de outra cultura" (CAMPOS, 2002, p. 72); 2) também desejávamos possibilitar que os estudantes se sentissem os donos de um conhecimento que despertava o interesse da entrevistadora.

Frequentemente, as identificações das espécies eram impregnadas de falas sobre diversos aspectos de sua biologia, relação com o manguezal e relação com a comunidade: dimorfismo sexual, ciclo de vida, hábitat, técnicas de coleta etc. Quando os temas não eram comentados espontaneamente, por motivos como condição de mínima tranquilidade, estudantes mais tímidos etc., formulava-se uma pergunta para abrir um caminho a essas explicações ("aonde mora?", "distingue o macho e a fêmea?, "você sabe se esse animal muda o casco?", "ouviu falar que o caranguejo está de leite?”, “já pescou alguma vez?”). No caso concreto da formulação da questão sobre a muda, às vezes, acontecia que o verbo "mudar" era interpretado como uma simples mudança de cor do tegumento, sendo que a pesquisadora refazia a pergunta utilizando outras expressões, tais como "trocar de casco" ou "largar o casco e fazer um casco novo", resgatadas das explicações de outros estudantes.

\section{Resultados e discussão}

A maior parte das identificações das 4 primeiras espécies (figuras 1A, 1B, 1C, 2A) foram feitas de forma imediata, de um a três segundos depois de ter observado o desenho, sem mostrar sombra de dúvida a respeito da própria resposta ("isso aqui é um caranguejo!! Dá para ver a diferença do caranguejo para o siri e do carangueio para o aratu" - Rafael).

No caso de Ucides cordatus (figura 1B), cabe notar que os estudantes de Baiacu, e coincidindo com os pescadores de Acupe (BA), aparentemente não utilizam nenhuma das denominações binominais (caranguejo-uçá, caranguejo-verdadeiro, caranguejo-comum) características de outras regiões do nordeste brasileiro (MACIEL; ALVES, 2009; NORDI, 1994; SOUTO, 2007), e denominam-no como, simplesmente, "caranguejo". Isto não significa que tais denominações binomiais não existam no repertório cultural da pesca na comunidade participante da pesquisa. Isto porque as diferenciações específicas dos nomes das espécies podem ser apenas de competência dos adultos mais experientes e conhecedores dessas espécies, ou, simplesmente, trata-se de um fenômeno denominado, por Berlin (1992), de reconhecimento linguístico polissêmico do protótipo de um gênero, no qual táxons subgenéricos podem ser rotulados por nomes primários. Nesse caso, isso ocorre quando o nome do subgenérico prototípico (a espécie morfologicamente mais representativa, genuína, ou o tipo ideal do grupo) é polissêmico com seu genérico superordenado, o que é comum em muitas classificações biológicas de comunidades tradicionais em todo o mundo (BERLIN, 1992). Estudos posteriores podem corroborar essas hipóteses.

A identificação de Callinectes sp. mostra a existência de um grupo etnotaxonômico denominado de "siris" que reúne várias espécies desse gênero. A maior parte dos estudantes identificou o desenho a que se refere o termo "siri” ("Aí é um siri" - Juliano) sem titubear, reconhecendo também a existência da grande variedade de "tipos" que esse nome inclui. Isto demonstra que existe similaridade, ao nível genérico, entre categorias biológicas locais, dos

Ciênc. Educ., Bauru, v. 20, n. 1, p. 159-173, 2014 
estudantes pescadores, e categorias científicas. Já alguns estudantes deixavam perceber que reconheciam a figura como pertencente ao grupo "siris", informando algumas variedades, sem especificar qual era a representada no desenho ("siri mole, têm vários tipos de siri" Camilo; "é uma espécie de siri, têm muitas espécies de siri. Não só tem esse tipo de siri, não. Têm outros tipos também" - Antônio; ou "o siri, por causa do formato dele. O casco é diferente do caranguejo e do aratu... têm uns que moram dentro da água e têm outros que moram dentro do mangue, o siri de vasa e o siri de mangue" - Roberto). Outras respostas explicitavam o tipo de siri que aquele desenho não representava ("o caxangá é diferente desse aqui" - Rafael) e, finalmente, outros identificavam a figura com um tipo particular de siri ("esse aqui é siri de vasa" - Gilmar) ou "o siri é um marisco que ele vive no mar. Tem dois tipos, um vive no mar, a gente chama siri de vasa... o outro siri vive no mangue, se chama siri de mangue. Esse siri aqui é meio lilás azulado [o de vasa] e o outro [do mangue] é meio esverdeado" - Bruno). Adiciona-se, a título de informação complementar, a correspondência entre os nomes vernaculares e científico dos tipos de siri registrada na comunidade de Acupe (SOUTO, 2007), na mesma região da Bahia de Todos os Santos. O autor observou a existência de polissemia (vários nomes vernaculares designando uma mesma espécie) tanto dentro de uma própria comunidade como entre comunidades diferentes e de homonímia (diferentes espécies identificadas pelo mesmo nome vernacular) entre diferentes comunidades. Contudo, só futuros trabalhos de etnotaxonomia e identificação científica permitirão estabelecer as relações pertinentes entre as categorias etnotaxonômicas de siris da comunidade de Baiacu e de outras localidades.

O desenho correspondente à espécie Cardisoma guanbumi foi identificado, inicialmente, como guaiamum. Sempre a posteriori, os estudantes informaram dois nomes utilizados para referir indivíduos machos ou fêmeas, guaiamum e pata-choca, respectivamente ("tem o guaiamum macho e tem a pata-choca que é o guaiamum também, só que é guaiamum fêmea" Juliano; "a fêmea se chama pata-choca e o macho é o guaiamum mesmo" - João). Trata-se de um caso de polissemia que responde à identificação sexual como critério determinante da nomeação. Fausto Filho (1989) informa que Von Ihering (1942) incluiu a denominação "patachoca" no seu Dicionário dos Animais do Brasil. No entanto, segundo o autor, "pata-choca" é um nome muito pouco conhecido no nordeste do Brasil. Gostaríamos de salientar que, na região específica de Baiacu, a referida designação foi frequente. Em várias ocasiões, para o siri e o caranguejo, os entrevistados utilizaram os dois gêneros para nomear os dois sexos ("esse é um macho. É o siri branco. E aqui é a siria... Ela é a mulher do siri branco" - dona Maria; ou "a carangueija também não cresce muito, quem cresce é o caranguejo" - sr. Paolo). Dona Maria e Sr. Paolo são pais de alunos e moradores da comunidade de Baiacu.

O amplo conhecimento empírico que os estudantes têm dessas espécies denota-se nas próprias justificações, mais ou menos gerais ou detalhistas, que acompanhavam as respostas. Enquanto uns estudantes debruçavam-se fazendo referência a aspectos e detalhes morfológicos característicos de cada espécie, sobretudo do casco e das pernas, mas, também, de outras estruturas ("pelo corpo que é pintado", "pelas pernas, porque têm uns cabelos" ou "pelo olho"), outros estudantes justificavam observações de caráter geral ("pelo jeito", "pelas aparenças dele", "tem umas características de caranguejo") ou, simplesmente, argumentavam a identificação com base na estreita familiaridade para com esses animais: "eu conheço", "no Baiacu tem muito" ou "porque em Cacha Prego eu vejo as moças pegar". 
Bejarano, N. R. R. et al.

O desenho representado na figura 2B, correspondente a uma espécie do gênero Uca sp., se mostrou como o único sem receber um consenso nas respostas dos estudantes. Os nomes "chama-maré" e "sarará", que parecem identificar uma mesma espécie, foram especificados por uma aluna natural de outra localidade de Vera Cruz, Barra Grande, que explicou: “eu conheço como chama-maré. Outras pessoas chamam ele de sarará. Ele mora na beira da praia. ele fica sempre localizado na areia" (Simone). Ainda que com escassa informação sobre a espécie, a denominação "sarará" aparece no Dicionário dos Animais do Brasil de Von Ihering (1942 apud FAUSTO FILHO, 1989). Outro estudante também de Barra Grande identificou-o como uma fase juvenil de um animal chamado "tesouro": "esse dai ele era um boinho pequeno e aí vai crescendo e vira um tesouro" (Pedro). Diferentes nomes foram dados pelos e entre os próprios estudantes de Baiacu. Enquanto, para uns, trata-se de um "caranguejinho" ("parece o caranguejinho, pela boquinha dele, pequena, uma boquinha pequena e uma boca maior, uma boca grande. Moram num buraco pequeninho. Quando a gente vê eles são um bucado, eles correm"), para outros, é um "tesourero" ou "tesouleiro" (tesurero, mora na lama, dentro do buraco, no apicum... andam vários, de cem a mais. Têm uma boca maior e uma menor, e sempre têm uma maior do que a outra, nunca fica igual" - Eraldo; ou "esse é o tesoulero. Vive no mesmo lugar que o caranguejo vive, na lama, dentro do buraco" - Rafael). Também houve quem mostrasse dúvida entre uma ou outra espécie, fato que parece indicar que os diferentes nomes vernaculares servem para identificar, pelo menos, duas espécies diferentes ("é tesoleiro ou caranguejinho. Esse aqui parece mais o tesoleiro. Gosta de ficar no barro, o caranguejinho fica mais em areias brancas. O tesolerio e maior que o caranguejinho" - Antônio) ou "para mim que é o tesoureiro. Não! o caranguejinho aqui!, o caranguejinho.. porque tem uma boca muito pequena. $\mathrm{O}$ tesoureuro tem uma boca maiorzinha assim, é igual ao caranguejinho, que não cresce, só fica deste tamanhozinho". Finalmente, apontar que, para dois estudantes, o caranguejinho (Uca sp) é a fase juvenil do caranguejo (Ucides cordatus).

De maneira geral, a forma como está estruturada a etnotaxonomia dos crustáceos Deacapoda: Brachyura, dos estudantes de Baiacu, ou seja, em táxons genéricos reconhecidos por suas características morfológicas, comportamentais e ecológicas e que são nomeados por lexemas primários, produtivos ou improdutivos, isto é, analisáveis ou não lexicamente; que se subdivedem em poucos táxons específicos, designados por nomes secundários, é consistente com alguns dos princípios universais de categorização e nomenclatura observados em sociedades tradicionais (BERLIN,1992). Contudo, os dados etnoxanômicos coletados nesse estudo não são suficentes para se realizarem comparações mais aprofundadas com outras etnotaxonomias do mesmo grupo de animais em outras comunidades pesqueiras, ou, mesmo, para testar a maioria dos princípios universais de classificação estabelecidos por esse etnobiólogo americano. Mesmo porque não era o objetivo principal da pesquisa provar essas hipóteses, mas, sim, demonstrar o conhecimento tradicional detalhado desses estudantes sobre a biologia dessas espécies, como ele era tratado na escola, e sua relevância como ponto de partida para um diálogo de saberes científicos e tradicionais no espaço escolar. 


\section{O cotidiano do ensino de ciências na Escola}

Foge dos objetivos desse trabalho fazer uma avaliação do PRFE. A escolha dessa escola que desenvolvia o projeto de regularização de fluxo foi absolutamente casual. Do nosso ponto de vista, a realidade do ensino de ciências no nivel Fundamental nas escolas públicas sofre, em maior ou menor grau, dos mesmos problemas dessa escola em particular. No que toca ao foco deste artigo - as relações entre os conhecimentos que os alunos possuem antes de sua educação formal e a relação desses conhecimentos com a própria educação formal -, a situação que observamos, nesse contexto particular, não difere em muito do que ocorre nas várias escolas públicas no Brasil. A perspectiva construtivista teve seu auge nas duas últimas décadas do século passado. Muitas pesquisas foram feitas sobre o conhecimento não formal dos estudantes. O maior legado contrutivista: "saiba o que seu aluno já sabe e ensine-o de acordo", foi esquecido para não dizer que talvez nunca, de fato, tenha sido algo que fizesse parte de forma estável dos cotidianos escolares.

Dito isso, passemos a examinar o que, de fato, se constitui como o cotidiano da escola estadual Carneiro Ribeiro. A escola, que funciona em horário matutino, vespertino e noturno, conta com um corpo docente de, aproximadamente, 25 professores, $48 \%$ dos quais com licenciatura plena (documento interno da escola).

Aqui reside um problema crucial: a formação dos professores. Cerca da metade dos professores não possuem formação inicial nas licenciaturas, o reflexo se dá no ensino praticado. Professores malformados, ou não formados, tendem a desenvolver seu ensino baseado apenas no livro didático. Estes desenvolvem, com seus alunos, cópias de trechos dos livros e evitam fugir desse roteiro porque sabem que podem ser surpreendidos com questões inusitadas. Por fim, o ensino, se é que podemos denominar essas ações como ensino, fica enfadonho, desestimulante, seja para os alunos e, por que não, também para os professores.

Especificamente em relação ao material didático (e, também, paradidático) distribuído para as escolas que aderiram ao PRFE, as avaliações feitas foram em duas direções. Por um lado, professores afirmavam que os livros estavam "além da capacidade de entendimento dos alunos". Já coordenadores pedagógicos envolvidos no projeto avaliavam que os professores estavam "aquém dos livros" ou não sabiam como trabalhar com eles. De maneira que, em se tratando dos materiais didáticos, eles não serviam a sua função precípua como mediador do conhecimento e estavam muito longe de ajudar a produzir aprendizagem (CRUZ; BARROS, 2008). Essa avaliação do livro didático, que parece contraditória, indica, em nosso entendimento, que a formação dos professores era tão precária que tampouco o livro poderia ajudar naquele contexto. Dizer que o livro está "além dos alunos" é descartar o uso do livro. Por outro lado, os próprios professores eram avaliados como não sendo capazes de utilizar o livro-texto, ou seja, estavam 'aquém do livro", segundo os coordenadores pedagógicos.

O ânimo dos alunos escolhidos para a pesquisa também não era muito bom. A professora Creuza (de português) relata assim a situação da turma:

“[...] nessa turma da manhã, eu não sei se a dificuldade maior é que noventa por cento dos estudantes, eles moram na localidade de Baiacu, acho que a dificuldade maior é o numero de vezes que esses estudantes repetem a $5^{a}$ série. O projeto é $5^{a}$ e $6^{a}$, mas já estão com a autoestima lá 
Bejarano, N. R. R. et al.

embaixo. Então, a dificuldade é que têm estudantes que entram na sala, sentam, batem papo e vão embora,... não se propõem a fazer as atividades".

Escutamos relatos de casos de alunos (não poucos) que se embriagam durante o trajeto da casa para a escola. Sendo que esses alunos ficam absolutamente sem condições de exercer qualquer atividade educativa nessas condições, embora, deva-se levar em conta que há relatos de professoras da escola que denunciam que a prática de ingestão de bebida alcoolica é comum, mesmo entre crianças na comunidade de Baiacu. Outro aspecto importante do cotidiano dos alunos, e que influencia diretamente o rendimento escolar deles, é o tempo que dedicam os alunos-pescadores ao trabalho. A rotina de um aluno-pescador inclui um turno escolar matutino (entre $8 \mathrm{~h}$ e 12h), além do trabalho pesqueiro. Nesse caso, um dia de pesca é assim relatado por um aluno-pescador:

“[...] quando saio à tarde para pescar..... Chega lá, espera dar sete e meia, abre a rede e começa a pescar e quando dá uma hora da manhã gente vem embora. Uma hora chega no porto, cata o camarão e sobe. Quando a gente chega em casa, uma e meia, duas horas da manhã. Tomo um banho e aí vou dormir, duas horas, três, quatro, cinco, seis? Durmo quatro horas de relógio, tomo o banho, tomo o café e venho para o colégio". (Bruno)

Deve-se ter em conta que é sempre o tipo de maré que determina o tempo de pesca. O caso de Bruno é extremo. Há casos em que um tipo de maré faz com que o pescador saia no final da tarde, retornando entre $20 \mathrm{~h}$ e $21 \mathrm{~h}$. Deve-se computar, nesse cronograma, o fato de o ônibus levar sessenta minutos para sair de Baicu e chegar na escola. Esse era o quadro em que se encontravam professores e alunos da escola no momento em que a pesquisa se iniciou.

\section{O livro didático adotado na Escola}

A pesquisa não tem dados empíricos de observações de aulas de ciências, embora muito tempo tenha se permanecido na escola e parte desse tempo em sala de aula. Vamos tecer breves comentários sobre o livro didático de ciências adotado, julgando que as aulas de ciências, em muito, se apoiavam nos conteúdos desses livros. Desse modo, estamos assumindo que as aulas de ciências estão estreitamente alinhadas com os conteúdos e as sequências dos livros didáticos.

O programa de Regularização do Fluxo Escolar adotou, para a disciplina de ciências, o livro "Ciências segmento A", volumes 1 e 2 (BAHIA, 2001). Os direitos de copyright são da Fundação Luis Eduardo Guimarães, tendo sido produzido pela Secretaria de Educação do Governo do Estado da Bahia. O livro pode ser usado da $5^{a}$ à $8^{a}$ série do Ensino Fundamental.

O volume 1 é composto de 15 unidades, no qual cada unidade é dividida em um certo número de aulas, de maneira que há noventa aulas distribuídas nessas 15 unidades. A própria divisão adotada pelo livro - aula a aula - nos dá a certeza que, de fato, as aulas de ciências para 
os alunos pescadores não fugiam muito do que contêm esses livros. Mais do que isso, as aulas de ciências ou eram réplicas dos livros ou roteiros seguidos rigorosamente pelos professores, aula a aula, como "apropriadamente" o livro já estava dividido. A divisão das unidades segue, grosso modo, aquela velha divisão conhecida como Água, Ar e Terra. De sorte que, a parte que compreende as unidades de 1 a 4 (e as aulas de 1 a 26) chama-se Planeta Terra. Na parte II, estuda-se "Os Seres Vivos do Planeta: como vivem como se reproduzem". Nessa parte II, estão as aulas 27 a 60. Na parte III, "Os elementos fundamentais da vida: água, ar, terra", que compreende até a aula 77. Por fim, na parte IV, "Os ecossistemas brasileiros", que vai da aula 78 à aula 90, falando da Mata Atlântica, Caatinga e do Cerrado.

Lembrando que nossos alunos pescadores são experts em manguezais e em pesca marinha, vejamos em que momento o livro do volume 1 poderia dialogar com os jovens pescadores. De noventa aulas do volume 1 do livro de ciências, encontramos duas aulas que, se fossem bem conduzidas, a escola descobriria atônita que seus alunos pescadores conheciam, a partir de sua experiência prática e vivência, um maior número de coisas do que o próprio livro informava e com mais detalhes do assunto dos que os próprios professores. Destacamos a aula 36 (unidade 6 - Os Invertebrados - Caranguejo não é peixe) e a aula 83 "O Manguezal santuário ameaçado" da unidade 13 (Mata Atlântica).

$\mathrm{Na}$ aula "Caranguejo não é peixe", logo na atividade 1, "identificando crustáceos", a primeira pergunta é: "Você já viu um camarão de perto? Poderia descrevê-lo?". Perguntar algo dessa natureza para um aluno pescador, que sai quase todo dia de sua vida para arrastar camarão, só pode levar a dois tipos de atitudes nos alunos: 1) se lhes fossem dado espaço e uma escuta cuidadosa, como fez a pesquisadora principal desse estudo, uma aula de anatomia e fisiologia de camarões, dada pelos alunos, poderia ocorrer ali mesmo, obviamente sem que os nomes científicos fossem citados; 2) mesmo sabendo que essa turma era formada por quase "90\% de moradores da comunidade de Baiacu", não temos notícia de que, nessa aula, houve mobilização dos alunos para que pudessem falar de suas experiências com a pesca de camarões. Talvez porque os alunos estivessem cansados, talvez porque o professor não se deu conta do público que compunha sua turma, talvez porque, de maneira absurda, os alunos pescadores façam as lições solicitadas pelo livro esquecendo o que sabem, ou julgam que o que sabem não vale naquele contexto; ou, ainda, o fato é que, na aula 36, falou-se sobre crustáceos e nada mudou para que pudesse deixar alunos e professores menos "desinteressados", para que pudesse ocorrer um encontro genuíno de conhecimentos. Esse estudo também registrou referências explícitas do vasto conhecimento sobre a preservação do ecossistema do manguezal dos alunos pescadores: sabem, por exemplo, que não se captura caranguejos pequenos, que não se deve capturar caranguejos no período da "andada do caranguejo", que se deve preservar caranguejos que estejam com ovos, criticam o uso de explosivos nas pescas no mar. Coincidentemente, as questões que se seguem, nas atividades propostas para essa aula, fazem três perguntas relacionadas a essas mesmas noções de preservação das espécies. $\mathrm{Na}$ atividade 2 , as questões são, após uma pequena consideração sobre o valor comercial de camarões e lagostas: "Por que alguns animais como camarões e lagostas, possuem grande valor comercial?”; "Qual o risco de um animal que possui grande valor comercial?" "O que muitos pescadores costumam fazer que prejudica a reprodução desses animais e ameaça sua sobrevivência?” Termina solicitando que os alunos reflitam sobre a "importância de conhecer o ciclo de vida de animais como os crustáceos para definir períodos de pesca em uma região" (BAHIA, 2001, p. 122-123). 
Bejarano, N. R. R. et al.

Vejamos se as respostas a essas questões não são dadas integralmente pelos alunos com seu conhecimento adquirido em seu cotidiano de pescadores: “às vezes muitas pessoas não têm nem essa noção, mais tem muitas pessoas que aproveitam o mangue, porque vivem dali, e por isso mesmo que eles pegam os macho. Por que o caranguejo anda? (andada)".

"O pessoal, a maioria, tem lugares que o pessoal não pega na andada, não pegam as fêmeas, pega sempre os machos. Porque tem que ser aproveitado! Por isso que hoje mutas pessoas às vezes vem no mangue e não pega um carangueijo, porque muitos não souberam aproveitar. Não tem caranguejo. $\mathrm{Na}$ minha região, o pessoal sai para Sete Barras para pegar o caranguejo e não consegue, porque lá acabou o caranguejo. Por que acabou? porque pegaram as fêmeas, não souberam aproveitar". (Simone)

Os jovens alunos pescadores reconhecem que a captura de fêmeas é prejudicial para eles próprios, mas também sabem que, se porventura uma fêmea for capturada, não implica 'catástrofe'. Mostram, também, absoluta consciência de que há um tamanho que é adequado para a captura. "Então, vocês não comem fêmeas?" [pergunta a pesquisadora].

"Não, não. Uma ou outra assim, às vezes quando a gente está com vontade de comer uma fêmea com ova, a gente pega uma outra e leva para poder a gente provar, que ali tem afrodisíaco, e é bom para os dente também, que tem cálcio, aí é bom. Não pode pegar não, se pegar arrisca a ficar preso. As fêmeas a gente soltamos para reproduzir, porque se a gente levar cada uma daquela fêmeas ali têm mais de de z mil filhotes. Se a gente levar uma vai ser ruim para gente, que depois não vai encontrar. Então o que a gente solta mais aqui é filhote e fêmea, e o resto a gente aproveita tudo". (Bruno)

A visão de preservação apresentada nesses trechos de falas de nossos alunos pescadores é contundente. Desnecessário comentar a atividade do livro proposta na aula 83 intitulada "Manguezal santuário ameaçado". Há, claramente, uma consciência sobre o que se pode e o que não se pode fazer em termos da atividade de captura no mangue, que, afinal de contas, é o lugar onde moram, bem como a base material de sua subsistência.

\section{Considerações finais}

Se durante as aulas dessa escola, no período que a pesquisa as acompanhou, detectou-se que não havia preocupações com os conhecimentos tradicionais dos alunos pescadores, a própria pesquisa oportunizou um diálogo entre esses dois saberes. Sete professores de diferentes áreas participaram ativamente da pesquisa com os alunos da comunidade de Baiacu. A professora Creuza adaptou suas aulas dedicadas ao estudo da confecção de cartões postais com a finalidade de realizar desenhos sobre a vida na comunidade; a prof ${ }^{a}$ Laila, de Geografia, 
adaptou uma aula sobre mapas para a realização de mapas da própria comunidade de Baiacu, e a professora Gal, de Ciências, sugeriu um debate sobre a vida ancestral na ilha de Itaparica como motivo do dia do índio, e cedeu outras aulas para a realização de desenhos de animais. Pudemos observar que a escola tomou consciência de um tipo de conhecimento que seus alunos tinham que estava sendo negligenciado.

Sem pretender fazer uma listagem detalhada, inequívoca e exata desses conhecimentos, optamos por anotar alguns deles. Centrando-nos naqueles conceitos tangentes à biologia dos organismos, especialmente dos braquiúros, e às relações ser vivo/meio ambiente, consideramos que as explicações dos estudantes, "traduzidas" na linguagem acadêmica, abrangem os seguintes conceitos: anatomia de braquiúros, funções da nutrição, relação e reprodução nos seres vivos e nos braquiúros em particular, ciclos vitais nos seres vivos e nos braquiúros em particular, adaptações anatômicas, fisiológicas e etológicas, biodiversidade, meio ambiente aquático e aéreo, biocenose, biótopo, hábitat e nicho ecológico, relações tróficas e impactos ambientais. Não pretendemos dizer, apresentando essa listagem, que os estudantes entram na sala de aula dominando os significados acadêmicos. Mas sim, queremos frisar que parte dos conteúdos conceituais que supostamente têm de ser trabalhados no ensino de ciências tem pontos de ligação com o conhecimento que os meninos e meninas já trazem desde suas comunidades, e que o ensino de ciências não deveria deixar de considerar esse aspecto.

Como este artigo toma apenas parte da pesquisa original, não pudemos apresentar os dados referentes a todos esses conceitos que elencamos acima e que acreditamos que os alunos possuem com um nível de profundidade que impressionou toda a equipe de pesquisadores. Por fim, acreditamos que, mesmo em escolas - com todas as dificuldades que se apresentavam nessa escola pesquisada -, pode-se, com um mínimo esforço, estabelecer diálogos estáveis entre os conhecimentos trazidos pelos estudantes e derivados de sua vivência e o conhecimento dito escolar ou científico. A melhora na autoestima dos alunos é evidente. A motivação dos professores se aguça. Por fim, todos ganham ao constatarem que nossos alunos detêm um conhecimento profundo, sofisticado e relevante sobre determinados assuntos que interessam diretamente à escola.

\section{Referências}

BAHIA. Secretaria da Educação. Ciências: segmento A - Programa de Regularização do Fluxo Escolar. Salvador: Fundação Luis Eduardo Guimarães, 2001. 2 v.

BAPTISTA, G. C. S. Importância da demarcação de saberes no ensino de ciências para sociedades tradicionais. Ciência \& Educação, Bauru, v. 16, n. 3, p. 679-694, 2010. Disponível em: < http://www.scielo.br/pdf/ciedu/v16n3/v16n3a12.pdf>. Acesso em: 06 fev. 2014.

BAPTISTA, G. S. C.; EL-HANI, C. N. Investigação etnobiológica e ensino de biologia: uma experiência de inclusão do conhecimento de alunos agricultores na sala de aula de biologia. In: TEIXEIRA, P. M. M. (Org.). Ensino de ciências: pesquisas e reflexões. Ribeirão Preto: Holos, 2006. p. 84-96. 
Bejarano, N. R. R. et al.

BERLIN, B. Ethnobiological classification: principles of categorization of plants and animals in traditional societies. Princeton: Princeton University Press, 1992.

BRUNET, J. M. S. Aratus, caranguejos, siris e guaiamuns, animais do manguezal: uma etnografia dos saberes, técnicas e práticas dos jovens da comunidade pesqueira de Baiacu (Ilha de Itaparica-Ba). 2006. 163 f. Dissertação (Mestrado em Ensino, Filosofia e História das Ciências) - Universidade Federal da Bahia, Salvador, 2006.

CAMPOS, M. O. Etnociência ou etnografia de saberes técnicas e práticas? In: SEMINÁRIO DE ETNOBIOLOGIA E ETNOECOLOGIA DO SUDESTE,1., 2002, Rio Claro. Anais... Rio Claro: SBEE, 2002. p. 47-92.

CRUZ, E. B. G. da; BARROS, M. J. F de. Projeto de regularização do fluxo escolar: profilaxia ou tratamento? Gestão \& Planejamento, Salvador, v. 9, n. 1, p. 56-76, 2008. Disponível em: <http://www.revistas.unifacs.br/index.php/rgb/article/view/232/736>. Acesso em: 06 fev. 2014.

DRIVER, R. et al. Ideias científicas en la infancia y en la adolescencia. Madrid: Ediciones Morata: Ministerio de Educación y Cultura, 1989.

DUARTE, N. (Org.). Sobre o construtivismo: contribuições a uma análise crítica. 2. ed. Campinas: Autores Associados, 2005.

EL-HANI, C. N; BANDEIRA, F. P. Valuing indigenous knowledge: to call it "science" will not help. Cultural Studies of Science Education, Dordrecht, v. 3, n.3, p. 751-779, 2008.

FAUSTO FILHO, J. Sobre os crustáceos decápodes referidos por Rodolpho Von Ihering no seu Dicionário dos Animais do Brasil (1942). Revista Ciência Agronômica, Fortaleza, v. 20, n. 01/02, p. 53-57, 1989.

MACIEL, D. C; ALVES, A. G. C. Conhecimentos e práticas locais relacionados ao aratu Goniopsis cruentata (Latreille, 1803) em Barra de Sirinhaém, litoral sul de Pernambuco, Brasil. Biota Neotropica, São Paulo, v. 9, n. 4, p. 29-36, 2009.

NORDI, N. A captura do caranguejo-uçá (Ucides cordatus) durante o evento reprodutivo da espécie: o ponto de vista dos caranguejeiros. Revista Nordestina de Biologia, João Pessoa, v. 9, n. 1, p. 41-47, 1994. Disponível em: <http://periodicos.ufpb.br/ojs2/ index.php/revnebio/article/view/16722>. Acesso em: 06 fev. 2014.

PERRELLI, M. A. S. Conhecimento tradicional e currículo multicultural: notas com base em uma experiência com estudantes indígenas Kaiowá/Guarani. Ciência \& Educação, Bauru, v. 14, n. 3, p. 381-96, 2008. Disponível em: <http://www.scielo.br/pdf/ciedu/ v14n3/a02v14n3.pdf>. Acesso em: 06 fev. 2014.

RODRIGUES, S. A. O manguezal e a sua fauna. São Paulo: USP: Centro de Biologia Marinha, 1995. Disponível em: <http://www.usp.br/cbm/artigos/mangue.html>. Acesso em: 01 mar. 2005.

SCHAEFFER-NOVELLI, Y. Manguezal: ecossistema entre a terra e o mar. São Paulo: Caribean Ecological Research, 1995. 
A vida de alunos pescadores ...

SCIENCE \& EDUCATION. New York: John Wiley, v. 6, n. 1-2, 1997. (Special issue on philosophy and constructivism in science education).

SOUTO, F. J. B. Uma abordagem etnoecológica da pesca do caranguejo, Ucides cordatus, Linnaeus, 1763 (Decapoda: Brachyura), no manguezal do Distrito de Acupe (Santo Amaro-BA). Biotemas, Florianópolis, v. 20, n. 1, p. 68-80, 2007.

TRÉZ, T. de A. e. Feyerabend, interculturalismo e etnobiologia: algumas possíveis articulações no ensino de Biologia. Biotemas, Florianópolis , v. 24, n. 3, p. 129-140, 2011.

Artigo recebido em 25/0713. Aceito em 06/12/13. 